\title{
A CONSTITUTIONAL APPROACH TO TAXES AND TRANSFERS
}

\author{
William A. Niskanen
}

\section{Introduction}

What are the characteristics of a "fair" system of taxes and transfers? All too often, contemporary political discussion of taxes and transfers uses a concept of fairness that provides little basis for agreement. A proposed change in taxes or transfers is usually considered fair only when it benefits one's own group or some other group that one favors, whether or not the existing taxes and transfers are fair by any standard. In this context, agreement is possible only if those who would pay higher taxes have some marginal benevolence toward those who would receive higher transfers (or lower taxes), given the existing distribution of income after taxes and transfers. Given the existing welfare state, this set of "Pareto optimal redistributions," a concept first developed by Harold Hochman and James Rogers (1969), may be empty. In this context, without such marginal benevolence, any system of taxes and transfers is a negative-sum game, a form of legalized theft, reducing the total income of the community. The conventional focus on the distributional outcomes of this game, thus, is not a sufficient basis for determining whether these outcomes are the results of a fair game.

This paper takes a "constitutional" or "contractarian" approach to taxes and transfers, and is based on a perspective first articulated by Frank Knight (1947), two applications first suggested by Richard Zeckhauser (1974), and a recent development of this perspective by James Buchanan (1985). As is so often the case, it is most appropriate to start with Knight. According to Knight (1947, p. 392):

Cato Journal, Vol. 6, No. 1 (Spring/Summer 1986). Copyright 9 Cato Institute. All rights reserved.

The author is Chairman of the Cato Institute and a former member of the President's Council of Economic Advisers. This paper summarizes one section of a longer paper, "A 'Constitutional' Perspective on Social Welfare Policy," prepared for a Ford Foundation conference on social welfare policy, November 3-5, 1985. 


\section{Cato Journal}

All problems of social ethics are like those of play in that they have the two components of obeying the rules and improving the rules, in the interests of a better "game." .. . As a matter of course, every party in the game must "play his own hand' to the best of his ability; otherwise there is no game. ... Further, rigorous equality in the distribution of the results is self-contradictory.... The ethical ideal is a 'fair' and an interesting game.

A constitutional approach to taxes and transfers, thus, addresses the rules of the game, rather than the results of a specific play of the game. The distinctive assumption of this approach is that each person selects the rules affecting later taxes and transfers without knowledge of his specific position in the post-constitutional distribution of natural endowments. Given a consensus on these rules, unanimous postconstitutional agreement is neither a necessary nor sufficient basis for judging the fairness of the outcomes. In this sense, this approach is strictly individualistic but not strictly libertarian. The promise of this approach is based on the prospect of a much broader consensus on these rules than on any post-constitutional decisions on policies affecting the distribution of income.

For each application of this approach, each person is assumed to have a general understanding of human behavior, know his own preferences, know the post-constitutional distribution of natural endowments, but not know his specific position in that distribution. In this sense, these examples are better characterized by uncertainty rather than ignorance. Two specific assumptions are common to both examples: For each individual, the utility of the outcomes is proportional to the square root of disposable income and leisure, but the general results are common to any utility function with a declining marginal utility of each condition. ${ }^{1}$ The distribution of natural endowments is symmetric, with a mean of $\$ 30,000$, about equal to the current U.S. net national product per worker, in the first example, and a mean of $\$ 15$ per hour, equal to $\$ 30,000$ for a 2,000 hour work year, in the second example.

\section{Redistribution of Unearned Income}

The first example demonstrates the effects of different distributions of future income, given that all income is "manna," that is, independent of human effort. ${ }^{2}$ Consider the following choice: An individual faces a lottery with a probability of .5 that he will receive

${ }^{1}$ Specifically, $U(y, z)=y^{5} z^{5}$, where $y$ is the level of income after' taxes and transfers, and $\mathrm{z}$ is the hours of leisure.

${ }^{2}$ This example was suggested but not developed by Zeckhauser (1974), 
an income of $\$ 12,000$ or $\$ 48,000$. A certain income of $\$ 30,000$ would maximize utility. For the assumed utility function, however, he would prefer any certain income higher than $\$ 27,000$ to this lottery and would be willing to pay the state up to $\$ 3,000$ to provide the taxtransfer program. Table 1 summarizes the results of this type of choice for three distributions of natural income.

The first implication of this example is that the level of taxes and transfers increases with the variance of natural income. The first column, for example, could represent the choice of someone selecting social insurance for his own generation, and the third column the choice of the same person for the social insurance available to his distant grandchildren. This comparison illustrates that the difference between a person's decision on a law or on a constitutional rule is a rnatter of the degree of uncertainty, not a different type of analysis. A second implication is that the constitutional rule would limit the range of taxes and transfers but may not specify the amount. For the conditions of the second column, for example, taxes may range from $\$ 18,000$ to $\$ 21,000$, and transfers may range from $\$ 15,000$ to $\$ 18,000$, depending on the distribution of the social rent. This rent, which increases with the variance of natural income, could be used to administer the tax and transfer system, finance the protective and productive services of the state, increase transfers or reduce taxes, or could be wasted by the state or in various forms of rent-seeking activities-an allocation that cannot be fully determined at the constitutional stage. In this case, since all income is "manna," disposable incomes would be equal at some level between the equivalent income and the average natural income.

For some, this example may suggest a constitutional basis for a substantial tax on estates. Such an interpretation, however, would be strictly correct only if the level and distribution of the estate is

\begin{tabular}{lrrr}
\hline \multicolumn{3}{c}{ TABLE 1 } \\
\multicolumn{3}{c}{ REDISTRIBUTION OF UNEARNED INCOME } \\
\hline \multicolumn{3}{c}{$\begin{array}{c}\text { Natural Incorne } \\
\text { (Dollars per Year) }\end{array}$} \\
\hline Minimum & 20,000 & 12,000 & 6,667 \\
Maximum & 40,000 & 48,000 & 53,333 \\
Equivalent Income & 29,142 & 27,000 & 24,428 \\
Minimum Transfer & 9,142 & 15,000 & 17,761 \\
Maximum Tax & 10,858 & 21,000 & 28,905 \\
Maximum Rent & 858 & 3,000 & 5,572 \\
\hline
\end{tabular}




\section{Cato Journal}

independent of the behavior of those who inherit the estate. In many cases, of course, people "earn" their inheritance by behavior that serves the interests of the person who leaves the estate. One should be cautious about weakening the ties that bind one generation to the next. Nevertheless, an inheritance is closer to "manna" than is most other forms of wealth, and there may be a constitutional consensus for a higher relative tax rate on income from this source.

\section{Redistribution of Earned Income}

A second example demonstrates the characteristics of the optimal tax and transfer system, given that taxes and transfers affect the hours worked, for a specific distribution of natural wage rates. ${ }^{3}$ For this example, the observed wage rate is equal to the natural wage rate, that is, taxes and transfers are assumed to affect hours worked but not the choice of jobs or an individual's investment in his skills. An individual faces a lottery with a 25 probability of a natural wage rate of $\$ 6, \$ 12, \$ 18$, or $\$ 24$ per hour. The sum of taxes and transfers in this case is assumed to be equal. That is, no amount of taxes are necessary to administer the tax and transfer system or any other role of the state. The annual earnings are based on 50 weeks of work per year. Table 2 summarizes the characteristics of the tax and transfer system that maximizes expected utility for these conditions.

The most important implication of this example is that the marginal tax rates decline as a function of earnings. This induces those who are most skilled at generating earnings to work more than those who are less skilled and leads to a higher variance of earnings than of the

\section{TABLE 2}

REDISTRIBUTION OF EARNED INCOME

\begin{tabular}{lrrrr}
\hline & \multicolumn{4}{c}{ Natural Wage Rate } \\
& \multicolumn{1}{c}{$\$ 6$} & $\$ 12$ & $\$ 18$ & \multicolumn{1}{c}{$\$ 24$} \\
\hline Hours Worked per Week & 27.8 & 41.5 & 46.7 & 49.7 \\
Annual Earnings & 8,347 & 24,900 & 42,016 & 59,584 \\
Annual Transfers or Taxes (-) & 6,095 & 1,222 & $-2,473$ & $-4,844$ \\
$\quad$ Average Tax Rate (\%) & -73.0 & -4.9 & 5.9 & 8.1 \\
$\quad$ Marginal Tax Rate (\%) & 33.3 & 25.6 & 17.6 & 9.4 \\
Annual Disposable Income & 14,442 & 26,122 & 39,543 & 54,740 \\
\hline
\end{tabular}

${ }^{3}$ This example was fully developed by Zeckhauser (1974). The numbers presented in Table 2 are only a scalar change of the Zeckbauser calculations plus the correction of one error. 
natural wage rate. Average tax rates, of course, increase with earnings, reflecting the redistribution of income from higher skilled workers. For this example, taxes and transfer payments are 5.4 percent of total earnings, and the variance of disposable income is only slightly less than the variance of natural wage rates. This example assumes that there is only one form of transfer payment, similar to a negative income tax. A superior solution may be to allow the poor to choose one of two forms of transfers, either a negative income tax or an earnings subsidy. Similar calculations for a tax and transfer system that includes an optional earnings subsidy, unfortunately, have not been developed.

Our current tax and transfer system differs from this example in two important ways. One, marginal tax rates are now much higher than the optimal rates for both the lowest and highest skilled workers. This reduces the hours worked and earnings of both of these groups. Second, government transfer payments are now about 13.5 percent of net national product, an amount that would be appropriate only if the variance of natural wage rates is much higher than in this example.

\section{Effects of Other Conditions}

For the same distribution of natural wage rates and the same utility function, any change in other conditions would reduce the total amount of transfers relative to this example. ${ }^{4}$ Any marginal tax rate on earnings leads people to choose more pleasurable jobs and to invest less in human skills. Any tax on the income from new investment would reduce the size of the complementary stock of physical capital. Any expenditure for the protective and productive services of the state would reduce transfers unless it leads to an offsetting increase in total income. Any waste of resources by the state or in private rentseeking activities would have a similar effect. Each of these probable conditions affecting the post-constitutional behavior of people and governments is realistic to expect at the constitutional stage and would lead to a lower preferred amount of transfers. And finally, the potential to emigrate or, with others, to secede from a state would limit the total amount of coercive transfers from any one individual to the difference between the value of residence in one state and that in the next best alternative, minus the personal costs of moving or of participating in an effective secession. Such rights of emigration and secession, moreover, are likely to be secured by a constitutional

${ }^{4}$ The qualitative effects of changing these other conditions on the level of transfers is developed in a recent paper by Buchanan (1985). 
consensus, because they are consistent with the principle of maximum compatible liberty.

\section{Conclusion}

Although some amount of social insurance may be preferred at the constitutional stage, a realistic consideration of these other conditions may lead to a set of constitutional rules that provides no authority for the redistribution of income. The U.S. Constitution, for example, provides no explicit authority for federal welfare programs. Article 1 , Section 8 , describes 18 specific powers of the federal government, without a hint that these powers authorize the redistribution of income or the provision of federal welfare services. The only constitutional authority for the modern welfare state rests on an obscure ruling by the Supreme Court in 1936, in United States v. Butler, that "the power of Congress to authorize appropriations of public money for public purposes is not limited by direct grants of legislative power found in the Constitution." Our contemporary national community may share a constitutional consensus for some amount of some types of federal transfers. Our contemporary problem, however, is that there are no effective constitutional limits on the amount or nature of these transfers.

\section{References}

Buchanan, James. "Coercive Taxation in Constitutional Contract." Working Paper, Center for Study of Public Choice, George Mason University, 1985. Hochman, Harold M, and Rogers, James D. "Pareto Optimal Redistribution." American Economic Review 59 (September 1969): 542-57.

Knight, Frank H. "The Sickness of Liberal Society." In Freedom and Reform: Essays in Economics and Social Philosophy, pp. 370-402. New York: Harper and Bros., 1947.

Zeckhauser, Richard. "Risk Spreading and Distribution." In Redistribution through Public Choice, pp. 206-28. Edited by Harold Hochman and George Peterson. New York: Columbia University Press, 1974. 